\section{Histological and histochemical analysis of the gastrointestinal tract of the common pipistrelle bat (Pipistrellus pipistrellus)}

\author{
S. Strobel,,1,2 J.A. Encarnação, ${ }^{1}$ \\ N.I. Becker, ${ }^{1}$ T.E. Trenczek ${ }^{2}$ \\ 1 Mammalian Ecology Group, Department \\ of Animal Ecology and Systematics, \\ Justus-Liebig-University of Giessen \\ 2Department of General Zoology and \\ Developmental Biology, Justus-Liebig- \\ University of Giessen, Germany
}

\section{Abstract}

Bats have a very high mass-specific energy demand due to small size and active flight. European bat species are mostly insectivorous and the morphology of the gastrointestinal (GI) tract should be adapted accordingly. This study investigated the general anatomy by histology and the function by analysing carbohydrate distribution in particular of the mucus of the GI tract of the insectivorous bat Pipistrellus pipistrellus. The GI tracts of three individuals were dissected, fixed in formaldehyde, and embedded in paraffin wax. The tissues and cells of the GI tract of $P$. pipistrellus were analysed by classical (acid alizarin blue, haematoxylin-eosin, and Masson Goldner Trichrome), histochemical (periodic acidSchiff, Alcian blue at pH 2.5) and lectin histochemical (lectins WGA and HPA) staining procedures. The GI tract of $P$. pipistrellus is organised into the typical mammalian layers. The short, narrow, and thin-walled esophagus is simple with a folded stratified squamous epithelium without glands but mucous surface cells secreting neutral mucus. The stomach is globular shaped without specialisation. Mucous surface cells produced neutral mucus whereas neck and parietal cells secreted a mixture of neutral and acid mucus. Chief cell surface was positive for $\mathrm{N}$-acetylglucosamine and the cytoplasm for $\mathrm{N}$-acetylgalactosamine residues. The intestine lacked a caecum and appendix. The small intestine was divided into duodenum, jejunum-ileum and ileum-colon. The epithelium consisted of columnar enterocytes and goblet cells. The large intestine is short, only represented by the descending colon-rectum. It lacked villi and the mucosa had only crypts of Lieberkühn. Towards the colon-rectum, goblet cells produced mucus with $\mathrm{N}$-acetylglucosamine residues increasing in acidity except in colon-rectum where acidity was highest in the base of crypts. Along the tube the surface of enterocytes was positive for
$\mathrm{N}$-acetylglucosamine and $\mathrm{N}$-acetylgalactosamine. All over the mucus filling the lumen of the GI tract was positive for $\mathrm{N}$-acetylglucosamine and increased in acidity in all parts except of the stomach.

In conclusion, the simple GI tract showed an anatomical reduction of tissue enabling for a short retention time and a reduction of the load carried during flight: short GI tract, lack of lymphoid tissue, missing of glands in certain regions, and a distinct pattern of mucus distribution, indicating different physiological functions of these areas. The GI tract of $P$. pipistrellus was typical for an insectivorous species probably representing the ancestral condition.

\section{Introduction}

To ensure survival and ecological success, animals have to maintain energy demanding processes like metabolism, growth, and reproduction. ${ }^{1}$ Therefore, animals have to intake, process, and allocate energy, proteins, and other nutrients. ${ }^{2}$ These requirements must be covered by food intake to assure survival. The conversion of food into metabolizable energy occurs in the gastrointestinal (GI) tract, which extends from the oral cavity to the anus. ${ }^{3}$ The general morphology and histology of the digestive organs are conserved among mammals, ${ }^{4}$ but animals differ interspecifically. ${ }^{5,6}$ The main variations can depend on phylogeny, ${ }^{7,8}$ diet, ${ }^{9}$ and energy demanding factors like locomotion. ${ }^{10}$

Phylogeny is an important factor explaining differences concerning variations in the GI tract of mammals. ${ }^{7,8}$ For example, morphological variations of the GI tract of desert rodents can be explained mainly by phylogeny. ${ }^{11}$ In contrast to that, phylogenetic affiliation in phyllostomid bats correlates with shifts in diet composition. ${ }^{12}$ These shifts are accompanied by changes in the GI tract. ${ }^{13}$ Therefore, it is most likely that phylogeny, diet composition, and digestion are closely linked to each other. Other influences causing variation in the GI tract are energy demanding factors like locomotion..$^{10}$ The active flight of birds and bats is a very energy demanding form of locomotion. ${ }^{14}$ These energetic costs increase with the carried load. To minimize flight costs by decreasing flight mass, the size of GI tract and the carried digesta load are reduced compared to similar sized non-flying animals. ${ }^{10}$ This correlates with decreased intestinal tissue in bats, ${ }^{15,16}$ leading to reduced digestive capacity and reduced carried loads. ${ }^{17}$ Therefore, flying animals have to trade-off a small intestinal size and high-energy demands. A possible strategy of bats is a higher density of villi enabling high intestinal paracellular absorption rates. ${ }^{17-19}$
Correspondence: Sara Strobel, Mammalian Ecology Group, Department of Animal Ecology and Systematics, Justus-Liebig-University of Giessen, Heinrich-Buff-Ring 26 (IFZ), 35392 Giessen, Germany.

Tel. +49.641 .9935761 - Fax: +49.641 .9935709 .

E-mail: Sara.Strobel@allzool.bio.uni-giessen.de

Key words: Chiroptera, esophagus, glycoconjugates, intestine, lectins, stomach.

Contribution: SS, JAE, NIB, TET, study design; SS, TET, experiments performing, data analysis and interpretation; SS, NIB, JAE, TET, manuscript writing; JAE, TET, contributed reagents, materials and analysis tools.

Conflict of interest: the authors declare no conflict of interest.

Acknowledgments: we thank E. Mühlbach and R. Keil from the Bat Group Hanover (BUND, Friends of the Earth Germany) for the animal samples. We further thank Y. Kühnel, C. von Bredow, A. Diebel and the Mammalian Ecology Group for their help during the study.

Received for publication: 16 January 2015. Accepted for publication: 17 March 2015.

This work is licensed under a Creative Commons Attribution NonCommercial 3.0 License (CC BYNC 3.0).

○C Copyright S. Strobel et al., 2015 Licensee PAGEPress, Italy

European Journal of Histochemistry 2015; 59:2477 doi:10.4081/ejh.2015.2477

Besides the form of locomotion, bats have very high mass-specific energy demands due to their small size and naked wing membranes resulting in an unfavourable volume to surface ratio. ${ }^{20}$ Therefore, the adaptations of the GI tract to the energy requirement should be remarkable. For instance the food intake in relation to body mass of bat species is increased compared to terrestrial similar-sized mammals ${ }^{21}$ but is limited by the small volume of the GI tract.22 Additional factors like the digestive efficiency and the closely linked retention time of ingested food could be an adaptation to these high energy demands of bat species. ${ }^{23,24} \mathrm{~A}$ higher digestive efficiency means a greater percentage of assimilation of the ingested energy. ${ }^{25}$ A longer retention time indicates that individuals need longer to digest and defecate a prey organism ${ }^{26}$ which generally leads to an increased digestive efficiency. ${ }^{23}$ However, it was demonstrated that bats have short retention times ${ }^{21}$ but high digestive efficiencies $^{24}$ compared to other mammals. For Chiroptera, many different dietary habits are described (e.g., frugivory, sanguivory, and insectivory). ${ }^{27}$ Therefore, many diet-dependent 
morphological and functional adaptions concerning the GI tract can be found. ${ }^{12,13,15,28}$ European bat species are mainly insectivorous and feed on a wide range of arthropods.$^{29}$ It is not surprising that the GI tract is generally specialised to an arthropod diet. ${ }^{30}$ However, it could differ depending on the degree of specialisation.

The outstanding characteristics in terms of energy demand and digestion makes it necessary to examine the GI tract of bat species with various dietary habits and phylogenetic backgrounds. With this data, it would be possible to explain differences and specializations in GI morphology.

Many studies describe the general morphology of the GI tract of bats..$^{13,31-34}$ However, most studies investigated parts of the GI tract in more detail, mainly the stomach. ${ }^{35-37}$ Furthermore, only a few investigations were carried out on microbats, ${ }^{31,32}$ and even less on vespertilionid bats ${ }^{33,38}$ and to our knowledge none on pipistrelle bats. In order to explain digestive characteristics and other potential implications in physiology and evolution of bats we need a better understanding of the anatomy and histology as well as a more detailed analysis of the histochemistry and mucus distribution of the complete GI tract of bats. Therefore, this study was conducted on a very widespread species in Europe, the common pipistrelle, Pipistrellus pipistrellus. ${ }^{39}$ The main prey items of this bat species are softbodied and small Diptera. ${ }^{27}$

A few studies on GI tracts of bats were conducted by histochemical methods. ${ }^{13,36,37,40}$ To determine the structural complexity of glycoconjugates, the main components of the mucus in the GI tract, lectin histochemistry is more precise than other methods. ${ }^{41}$ Only the GI tract of one rhinolophid bat and three African bats were studied using lectin histochemistry. ${ }^{42,43}$ Therefore, a combination of classical histology, histochemistry and lectins-binding techniques was used to study the GI tract of $P$. pipistrellus.

This study describes i) the general anatomy and histology and ii) the potential function of the GI sections by variation in mucus distribution of the GI tract of the insectivorous bat $P$. pipistrellus. Our results allow an interspecific comparison of GI tract characteristics between species. These are interpreted in the light of functional adaption to digestive physiology that is related to the flight associated energetic requirements.

\section{Materials and Methods}

\section{Animals}

The anatomy and histology of the GI tract of two females and one male $P$. pipistrellus was studied. Torpid bats died due to a shock caused by construction works on a building which was used as roost. Dead bats were delivered almost immediately to a voluntary foster home. Dead bats were frozen without delay.

According to the German Animal Welfare Act [TSchG $\$ 4(3)]$ and to the Federal Nature Conservation Act [BNatSchG $\S 45$ (4)] no permission is required for the work on carcasses.

\section{Sample preparation}

To guarantee tissue quality and comparability of histology, histochemistry and lectin-binding, only freshly dead and immediately frozen carcasses without signs of putrefaction were used in this study. Carcasses were stored at $-80^{\circ} \mathrm{C}$ until use even though cytological preservation is more reproducible in bats than in other species. ${ }^{35}$

After determination of species, sex and age by visual inspection the body mass was measured (CM 150-1N, accuracy $0.01 \mathrm{~g}$ ). The abdominal wall was opened, the GI tract was removed, washed with $0.9 \%$ sodium chloridesolution and dried on filter paper. Afterwards, it was cut into six sections (esophagus, stomach, duodenum, jejunum-ileum, ileum-colon and colon-rectum). Landmarks for identification of these parts were described in detail by
Ishikawa and colleagues. ${ }^{34}$ For the intestine for instance, the main characteristics were topography and external appearances in combination with microscopic features (e.g., presence and length of villi, number of goblet cells) ${ }^{34} \mathrm{As}$ there was no clear distinction between duodenum and jejunum-ileum, only the part which ran transversely from the distal end of the pylorus towards the right abdominal wall before it curved caudally and continued beneath the jejunum-ileum was used for duodenal analysis.

\section{Tissue preparation}

The tissues were fixed with $4 \%$ formaldehyde in tris-buffered saline (TBS) and dehydrated by a graded ethyl alcohol (EtOH, Carl Roth GmbH, Karlsruhe, Germany) series increasing in concentration $(30 \%, 50 \%, 70 \%$, $80 \%, 90 \%$ ) diluted in TBS, and finally in $100 \%$ $\mathrm{EtOH}$. The EtOH was then replaced by isopropyl alcohol (Carl Roth $\mathrm{GmbH}$ ) before they were embedded in paraffin wax (Histosec $®$, Merck KG, Darmstadt, Germany) and mounted. The paraffin block was cut into thin sections (4-8 $\mu \mathrm{m}$ thickness) using a sledge microtome (Leica Microsystems, Wetzlar, Germany). Each GI section (esophagus, stomach, duodenum, jejunum-ileum, ileum-colon and colon-rectum) was cut in three blocks with intermediate pieces of $400 \mu \mathrm{m}$ in length between blocks. These separating pieces of tissue between blocks were discarded. Serial sections were prepared on glass slides (Carl Roth $\mathrm{GmbH}$ ) precoated with $0.2 \%$ chrome alum- $0.5 \%$ gelatine subbing solution (Merck KG). Afterwards, the sections were deparaffinised and rehydrated by a graded EtOH series decreasing in concentration $(98 \%, 90 \%, 70 \%, 50 \%, 30 \%)$ ending in water. After drying the samples were stored dust-free until further use.

\section{Anatomy and morphology of the gastrointestinal tract: classical and histochemical histology}

For classical histology the tissue sections of

Table 1. Lectins and corresponding source, carbohydrate binding specificity, inhibitory carbohydrate, used concentration, and fluorescent conjugate (labelling).

\begin{tabular}{|c|c|c|}
\hline & \multicolumn{2}{|c|}{ Lectin } \\
\hline & Helix pomatia agglutinin & Wheat germ agglutinin \\
\hline Acronym & HPA & WGA \\
\hline Source & Helix pomatia & Triticum vulgaris \\
\hline $\begin{array}{l}\text { Binding specificity } \\
\text { Inhibitory carbohydrate }\end{array}$ & $\begin{array}{l}\text { GalNAc47 } \\
\text { GalNAc** }\end{array}$ & $\begin{array}{c}\mathrm{GlcNAc}^{48}>>\mathrm{Neu} \mathrm{Ac}^{49} \\
(\mathrm{GlcNAc})^{3}>(\mathrm{GlcNAc})^{2}>\text { GlcNAc } \\
>>\text { Neu } 5 \mathrm{Ac}>>\text { GalNAc* }^{*}\end{array}$ \\
\hline Concentration (mg/mL) & 0.005 & 0.025 \\
\hline Fluorescent conjugate & TRITC & FITC \\
\hline
\end{tabular}

FITC, fluorescein isothiocyanate; Gal, galactose; GalNAc, N-acetylgalactosamine; GlcNAc, N-acetylglucosamine; Neu5Ac, N-acetylneuraminic acid (sialic acid); TRITC, tetramethylrhodamine; *according to the original data sheet provided by manufacturer. 
two individuals were stained with staining procedures modified after Mulisch and Welsch. ${ }^{44}$

For general morphological observations the acid alizarin Blue (AAS), haematoxylin-eosin (HE), and Masson Goldner trichrom (MT) staining were used. For histochemical analysis, periodic acid Schiff stain (PAS) and a combination of PAS with Alcian blue 8GX at pH 2.5 (PAS-AB) were used. For one individual, only HE and PAS was applied.

The two histochemical stains PAS and PAS$\mathrm{AB}$ were used to demonstrate the full complement of glycoconjugates. With PAS, glycogen, glycoproteins, neutral carbohydrates and neutral mucins are stained based on the presence of aldehyde groups and thus the monosaccharide unit structure. ${ }^{44-46}$ In addition, acid mucins containing significant quantities of sialic acid can be detected. ${ }^{44,45}$ In PAS-AB staining $(\mathrm{pH}$ 2.5), neutral (magenta), acid (carboxylated and sulphated polysaccharide chains; blue) and mixed neutral and acid (purple) mucins can be distinguished. ${ }^{45,46}$ After staining, the sections were dehydrated with Roticlear ${ }^{\circledR}$ (Carl Roth $\mathrm{GmbH}$ ) and embedded in mounting media (Entellan ${ }^{\circledR} \mathrm{Neu}$; Merck KG).

\section{Function of the gastrointestinal tract: lectin histochemistry}

Different fluorochrome-labeled lectins, that of Triticum vulgaris (WGA; FITC) and of Helix pomatia (HPA; TRITC) (Sigma-Aldrich, St. Louis, M0, USA) in $0.5 \%$ bovine serum albumin (BSA, Applichem) in TBS (pH 7.5) were used to define the distribution of specific glycosidic residues (Table 1). ${ }^{47-49}$ These lectins bind to glycoconjugates of GI structures of many mammalian species ${ }^{50}$ enabling the comparison of intra- and interspecific differences in glycoconjugates distribution.

Slightly modified after Brooks and Hall, ${ }^{51}$ the tissue sections were blocked with 3\% BSA-TBS (pH 7.5) containing 0.1\% Tween-20 (Carl Roth $\mathrm{GmbH}$ ) for $1 \mathrm{~h}$ at RT, followed by lectin incubation for $1 \mathrm{~h}$. Then, they were washed four times with TBS and counterstained with 4,6-diamidino-2-phenylindole dichloride (DAPI, $0.05 \%$ in TBS, AppliChem GmbH, Darmstadt, Germany) for $5 \mathrm{~min}$ to visualize cell nuclei. Sections were rinsed in TBS and mounted with Diazabicyclooctan (DABC0, Sigma-Aldrich). To control for autofluorescence of the respective tissue, a negative control was processed the same way but without lectin incubation on each slide. The samples were stored at $4^{\circ} \mathrm{C}$ in the dark until microscopic analysis (Olympus BX60 F-3) by two independent observers (SS, TET) to guarantee comparability. Digital images were generated using an Olympus Altra 20 camera.

\section{Results}

The GI tract of $P$. pipistrellus was organised in four layers: the innermost tunica mucosa, followed by the tela submucosa, the tunica muscularis and the surrounding tunica serosa or adventita. The tunica mucosa was divided into three distinct layers, i.e., the epithelium directed towards the lumen, the lamina propria, a layer consisting of connective tissue, and the lamina muscularis containing muscle fibres. No differences between sexes or individuals were observed. Binding of the two lectins HPA and WGA differed in the tissue sections (Table 2).

\section{Esophagus}

In general, the esophagus was narrow and thin-walled. The inner part had a star-shaped appearance where the mucosa built six plicae (Figure 1A). The oesophageal lumen was lined with a stratified squamous epithelium. The epithelium could be distinguished from the lamina propria due to the closely packed basal cells of the epithelium leading to a darker colour in classical histological staining (Figure 1A). The tela submucosa containing connective tissue was found directly above the tunica mucosa. No glands were observed. Mucous sur-

Table 2. Lectin labelling patterns and histochemical staining of the gastrointestinal tract of $P$. pipistrellus. Staining intensities and locations are given. For PAS-AB observed colour and mucus characteristics are specified.

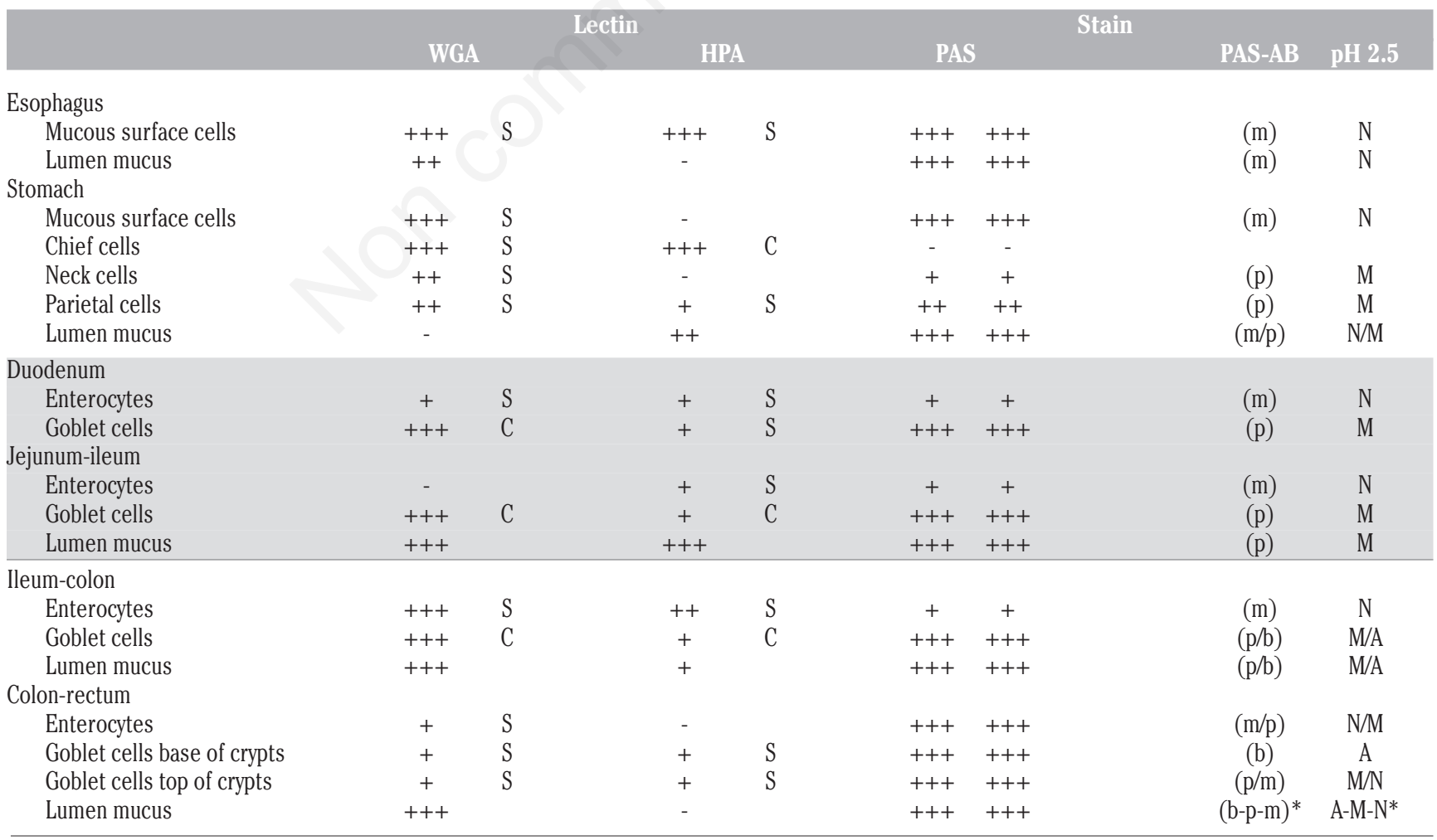

+++, strong positive; ++, positive; +, weak positive; -, negative; *, from the base to top of the crypt; b, blue; m, magenta; p, purple; A, acid carbohydrates, C, cytoplasm; M, mixed carbohydrates; N, neutral carbohydrates; S, surface. 
face cells and the mucus filling the lumen were positive for PAS and PAS-AB indicating neutral carbohydrates (Figure 1A, insert).

Binding of the WGA-lectin was strong close to the surface of the tunica mucosa (Figure 1B) and labeled the content of the oesophageal lumen. Similarly, the HPA-lectin labelling was detected on mucous cell surfaces at the epithelial site directed towards the oesophageal lumen (Figure 1C). In contrast to WGA, the HPA-lectin did not react with any luminal structures.

\section{Stomach}

The stomach was globular shaped with a rounded fundus. The cardiac and pyloric ends were found close to each other. The tunica mucosa was organised in large rugae (Figure
1D). They consisted of tunica mucosa (m) and tela submucosa (sm; Figure 1D). The structure and number of rugae differed in the samples. In all three specimens stomach contents, such as insect legs, were found.

The stomach was organized in four layers. Gastric glands and gastric pits (gp; Figure 1E, right) were observed. Cytoplasmic content as well as secreted mucus of mucous surface cells was strongly positive for neutral carbohydrates (Figure 1E, left, asterisk). Along the glands different cell types were identified (Figure 1D, right; Figure 1E, left and right). Towards the lumen, large, oval-shaped cells positive for a mixture of neutral and acid carbohydrates were observed (parietal cells, pc; Figure 1E). The luminal surface of neck cells was weakly positive for the same mixture of carbohy- drates. At the base of the glands smaller roundshaped cells negative for PAS and PAS-AB were found (chief cells, cc; Figure 1 D,E). In AAS stain, the base (b), neck (n) and isthmus (i) of gastric glands were distinguishable (Figure 1D, right). The lumen of the stomach was filled with neutral and mixed mucous material.

The signal of the fluorochrome labelled WGA-lectin was strong at the basal cell surface of chief cells, medium at the surface of neck and parietal cells in the neck region and weak at the top of glands. In contrast, mucus cells surfaces directed towards the lumen at gastric pits reacted strongly with the WGA-lectin (Figure 1F, left). The cytoplasm of chief cells at the base of the gastric glands reacted with the HPA-lectin (Figure 1F, right). Neck cells were negative and the surface of parietal cells was
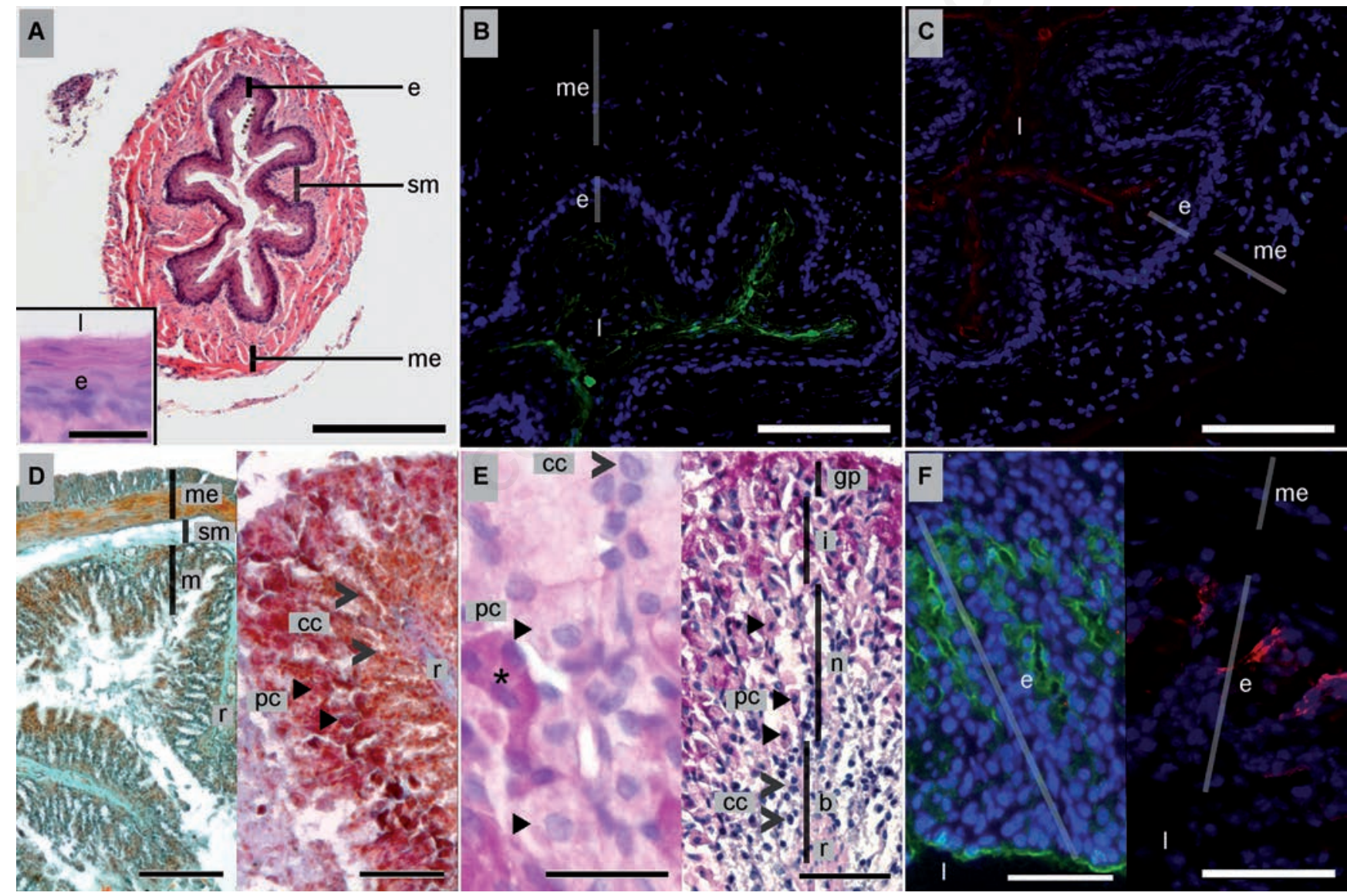

Figure 1. Histology, histochemistry and lectin-binding of the esophagus (A-C) and stomach (D-F) of P. pipistrellus. For classical histology, HE, MT and AAS stains were used. Histochemistry was done using PAS and PAS-AB (pH 2.5) stains. Lectin histochemistry was conducted with FITC-WGA (green) and TRITC-HPA (red) and nuclei counterstain with DAPI (blue). A) HE; scale bar: 500 um; insert: neutral carbohydrates; PAS; scale bar: $20 \mu \mathrm{m}$. B) Mucus in the lumen and on surface of epithelial cells bound by WGA (green) / DAPI (blue); scale bar: $200 \mu \mathrm{m}$. C) Mucus positive for HPA (red) / DAPI (blue); scale bar: $200 \mu \mathrm{m}$. D) Left: MT; scale bar: $500 \mu \mathrm{m}$; right: rugae; AAS; scale bar: 200 um. E) Different cell types along the gastric gland, left: PAS; scale bar: 10 um; right: PAS-AB; scale bar: 100 $\mu \mathrm{m}$. F) Carbohydrate detection; left: by WGA (green) / DAPI (blue); scale bar: $200 \mu \mathrm{m}$; and right: by HPA (red)/DAPI (blue); scale bar: $200 \mu \mathrm{m}$. b, base; >cc, chief cells; e, epithelium; gp, gastric pits; $\mathrm{i}$, isthmus; 1, lumen; m, mucosa; me, muscularis externa; $\mathrm{n}$, neck; $\square$ pc, parietal cells; sm, submucosa; $r$, rugae; *, mucous surface cells. 
only weakly positive for HPA-lectin. The HPAsignal became even weaker towards the top of the gland (Figure 1F, right). Mucous surface cells at gastric pits did not react with the HPAlectin.

\section{Intestine}

The intestine was short and lacked caecum and appendix. In the tela submucosa of the intestine no glands or lymphoid tissue were found. The intestinal parts (small intestine: duodenum, jejunum-ileum, ileum-colon; large intestine: colon-rectum) were quite similar to each other with a few exceptions as described below. The large intestine was short and only represented by the colon-rectum.

\section{Small intestine: duodenum}

The tunica mucosa of the duodenum built long finger-shaped evaginations (villi, v; Figure 2A). They filled the lumen of the duodenum. With increasing length of the villi, they formed a zigzag formation. In addition, tubular channels at the base of the villi were observed throughout the duodenum (crypts of Lieberkühn, c; Figure 2A). In cross sections these duodenal glands often appeared as round structures because they inclined rearwards. The single-layered epithelium consisted of two types of cells: enterocytes (ec) and goblet cells (gc; Figure 2A). The highly prismatic enterocytes were characterised by a basal cell nucleus and a less structured cytoplasm. At their apical cell surface neutral carbohydrates could be detected. Goblet cells could be identified by localisation of the secreted PAS positive mucus (Figure 2A). Using PAS-AB staining, also the presence of mixed, i.e., neutral and acidic carbohydrates could be documented. Goblet cells were more abundant in the villi than in the crypts (Figure $2 \mathrm{~A}$ ). In addition, an increasing number of goblet cells occurred along the duodenum towards the large intestine. No Brunner's glands were found. The cell surfaces of enterocytes and goblet cells directed towards the lumen were weakly positive for HPA-lectin binding (Figure 2B). The WGA-lectin signal was strong in the cytoplasm of goblet cells (Figure 2C) and weak at the surface of enterocytes.

\section{Small intestine: jejunum-ileum}

The following part of the GI tract is referred to as the jejunum-ileum because jejunum and ileum could not be distinguished due to missing clear differences between these parts. The jejunum-ileum of the small intestine was the longest part of the intestine. The organisation was quite similar to the duodenum with similar staining and labelling characteristics.

Zigzag formation of the mucosa similar to those of the duodenum was visible in the anterior part of the jejunum-ileum (Figure 2D).
Goblet cells were more abundant towards the ileum-colon, mainly located in the villi. Goblet cells (Figure 2E) and the mucus within the duodenal lumen were positive for PAS. PAS-AB stain indicated a mixture of neutral and acid carbohydrates (Figure 2E, left). Apical surfaces of enterocytes were weakly positive for neutral carbohydrates (Figure 2E, left). These similar results for duodenum and jejunum-ileum were reflected in the lectin labelling. Cell surfaces of enterocytes and cytoplasm of goblet cells lining villi and crypts reacted weakly with the HPAlectin (not shown). The WGA-lectin bound weakly to the cytoplasm of the goblet cells (Figure 2F). In contrast, the mucus filling the lumen of this part of the GI tract reacted strongly with both lectins.

\section{Small intestine: ileum-colon}

The ileum-colon was identified mainly on the basis of its topography. It ascended cranially from the caudal abdominal cavity. This situation corresponds to that of the mid of colon of other mammals. As villi were observed, these sections were considered to belong to the small intestine. The ileum-colon of the small intestine was quite similar to the duodenum and the jejunum-ileum. The number of villi and crypts decreased even further compared to the previous parts of the intestine (Figure 2G). Enterocytes and goblet cells could be hardly distinguished due to the dominant material consisting of mixed and acid carbohydrates in the lumen (Figure 2H). However, goblet cells were strongly positive for mixed and acid carbohydrates whereas enterocytes were weakly positive for neutral ones at the apical surface (Figure 2H, left).

The HPA-lectin signal was weak in the cytoplasm of goblet cells and the lumen. Enterocyte surfaces were positive for HPA-lectin binding. In contrast, sections treated with the WGAlectin showed strong fluorescence for all these structures (Figure 2I).

\section{Large intestine: colon-rectum}

The clear indication for the beginning of the large intestine is the disappearance of villi. Colon and rectum could not be distinguished as the diameter of the intestine did not change in this portion of intestine. The short colonrectum was the only part of the intestine representing the large intestine. A descending part could be observed whereas the ascending and transverse parts were absent. The colonrectum demonstrated the histological characteristics similar to the other intestinal parts.

Only crypts but no villi were present in colon-rectum (Figure 2J). These were densely packed and reached into the lamina muscularis. The lamina propria (lp) was reduced compared to the other parts of the intestine. PAS-AB stain detected neutral and acid carbo- hydrates (Figure $2 \mathrm{~K}$, left acid and right neutral). Cytoplasmic, cell bound and secreted glycoconjugates at the base of the crypts were acidic. In the middle the luminal glycoconjugates were partly mixed and at the top of the crypts, the carbohydrates were almost neutral. Enterocytes were positive for mixed carbohydrates with neutral ones dominating.

The signals of both the HPA- and WGA-lectin were very weak at the luminal directed surfaces of goblet cells at the base and the top of the crypts (Figure 2L, left). WGA-lectin bound additionally to mucus in the lumen and only in low number to enterocyte surfaces (Figure 2L, right).

\section{Discussion}

\section{Esophagus}

The narrow, thin-walled esophagus was simple, with a stratified squamous epithelium folded into longitudinal plicae, very fine submucosa, and had no glands. In mammals the number of oesophageal glands differs between species. $^{52}$ For example the shrew Cryptotis parva lacks oesophageal glands, ${ }^{53}$ whereas the mole Scalops aquaticus has glands in the submucosa. ${ }^{52}$ The lack of glands is observed in several insectivorous bats, e.g., Eptesicus fuscus $^{52}$ Rhinolophus ferrumequinum, ${ }^{42}$ and Myotis lucifugus. ${ }^{38}$

Bats have to cover high energy demands and maintain flight performance. ${ }^{22}$ Therefore, it is essential to reduce the load carried, e.g., by a short retention time ${ }^{21}$ in combination with a high digestive efficiency. ${ }^{24}$ This is achieved, for example by using exogenous instead of stored lipids to enable the fast assimilation. ${ }^{54}$ It is conceivable that the only function of the esophagus is the fast transport of ingested food $^{42}$ and salivary digestive enzymes, e.g., lipase ${ }^{55}$ into the stomach without oesophageal predigestion. Digestion in insectivorous bats seems to begin in the stomach, where the essential enzymes can be found, e.g., chitinase. ${ }^{28}$

Lectin labelling revealed that the lectins WGA and HPA bound to the surface of epithelial cells. These results indicate that the cell surface glycocalyx contains mucus glycoconjugates with $\mathrm{N}$-acetylglucosamine (GlcNAc), and the disaccharide galactose $\mathrm{B}-1-3 \mathrm{~N}$-acetylgalactosamine (Gal $ß-1-3$ GalNAc). This glycocalyx in combination with keratinized cells is a barrier to protect the tissue from pathogens and gastric contents as acids and pepsin which can reflux into the esophagus. Intercellular glycoconjugates containing GlcNAc can prevent the transport of protons across the epithelium via the transcellular route ${ }^{56}$ which otherwise leads to injuries of the epithelium. ${ }^{57}$ The content of 

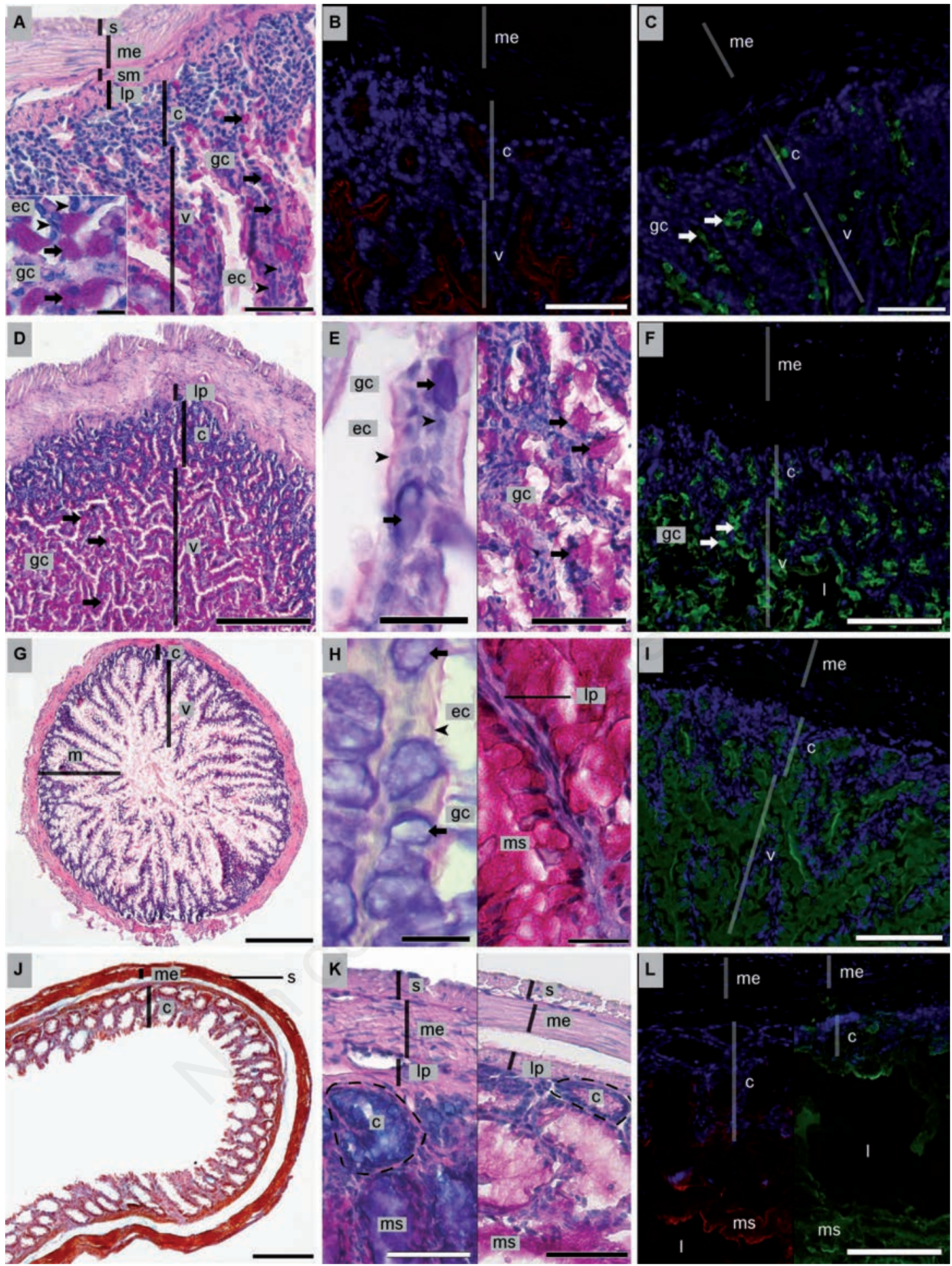

Figure 2. Histology, histochemistry and lectin-binding of the intestine [(A-C) duodenum; (D-F) jejunum-ileum; (G-I) ileum-colon; (J-L) colon-rectum] of P. pipistrellus. For classical histology, HE and AAS stained sections are shown. Histochemistry was conducted using PAS and PAS-AB (pH 2.5) stains. Lectin histochemistry was done with FITC-WGA (green) and TRITC-HPA (red) and nuclei counterstain with DAPI (blue). A) PAS; scale bar: $100 \mu \mathrm{m}$; insert: PAS-positive goblet cells; scale bar: $20 \mu \mathrm{m}$. B) Cell surfaces positive for HPA; scale bar: $200 \mu \mathrm{m}$. C) WGA-positive goblet cells; scale bar: $100 \mu \mathrm{m}$. D) PAS; scale bar: 500 um. E) Goblet cells positive for glycoconjugates; left: PAS-AB; mixed mucus of goblet cells, neutral glycoconjugates at luminal surfaces of enterocytes, scale bar: 20

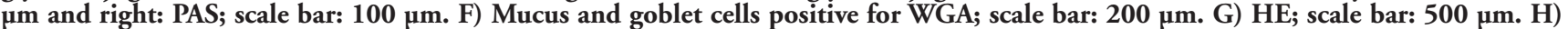
Luminal cell surfaces of enterocytes and mucus and cytoplasm of goblet cells positive for left: PAS-AB; scale bar: $20 \mu \mathrm{m}$ and PAS; scale bar: $40 \mathrm{\mu m}$. I) Goblet cells positive for WGA; scale bar: $200 \mathrm{\mu m}$. J) AAS; scale bar: $1 \mathrm{~mm}$. K) Left: PAS-AB: crypts with acidic glycoconjugates; scale bar: $100 \mu \mathrm{m}$; right: PAS; scale bar: $200 \mu \mathrm{m}$. L) Left: epithelial cell surface of goblet cells positive for HPA and right: WGA- binding of cell surfaces and luminal mucus; scale bar: $200 \mu \mathrm{m}$. c, crypts; > ec, enterocytes; $\rightarrow$ gc, goblet cells; 1, lumen; lp, lamina propria; $\mathrm{m}$, muscularis externa; ms, mucus; s, serosa; sm, submucosa; $v$, villi. 
the esophagus was PAS positive, indicating neutral mucus, and showed WGA-binding. As the major binding carbohydrate of the lectin WGA is GIcNAc and as it has a much higher affinity to GlcNAc than to sialic acid (Table 1), this leads to the assumption that the lumen of the esophagus contained glycoconjugates with peripheral GlcNAc. Due to missing secretory glands in the esophagus, these are most probably secreted by mucous surface cells or they are components of saliva. For saliva of Rattus norvegicus similar binding patterns can be found. ${ }^{58}$ Salivary mucins act as a protective gel of the mucosa and as a lubricant in the esophageal lumen..$^{5}$

\section{Stomach}

In general, insectivorous bat species have a simple and short GI tract. ${ }^{30}$ Most species have a simple globular stomach without specialisation. ${ }^{60}$ A similar pattern was observed in P. pipistrellus. In contrast, the nectarivorous bat Leptonycteris sanborni has a more saccular formed stomach indicating an adaption to a low-protein diet and higher food intake volumes than insectivorous bats. ${ }^{37}$ The stomach was organised into the four typical layers. In general, the histochemical analysis demonstrated that neutral mucosubstances were predominant. Mucus secreted by the surface cells was neutral whereas neck and parietal cells produced a mixture of neutral and acid mucus, most likely composed of neutral and acid carbohydrates. Similar results were demonstrated for many other mammalian species. ${ }^{50,61}$ Neutral mucus secreted by surface cells protects own tissue from the acid milieu of the stomach. ${ }^{62}$ The secretion of neutral carbohydrates is also known for mucus surface cells of e.g., humans, rats and rabbits. ${ }^{50,63}$ However, for some species, e.g., rhesus macaque, bison and cat acid mucins can be detected. ${ }^{50}$ Apart from the protection against acid, secreted mucus in the GI tract have other physiological functions, e.g., in lubrication, protection from pathogens, and epithelium reparation. ${ }^{64}$

The typical mammalian gastric gland, also described for insectivorous bat species, e.g., Myotis lucifugus, ${ }^{35}$ consists of four different cell types: parietal cells, mucous neck cells, argentaffin cells and chief cells. However, only parietal, mucous neck and chief cells could be differentiated. This might be explained by the high similarities of these cells in light microscopy and the rarity of the argentaffin cells. $^{35}$ The cells in the stomach of $P$. pipistrellus were morphological comparable to those of the bat Plecotus townsendii. ${ }^{15}$ Differentiation between chief and mucous neck cells was possible on the basis of the position of these cells along the gland. Chief cells are located at the base, whereas mucous neck cells are prominent at the isthmus and neck of the gastric glands. ${ }^{35}$ In addition, these areas were stained differently with AAS, probably due to the specific granules and the molecular characteristics of mucous neck cells ${ }^{35}$ and thus documenting different functions of these cell types. ${ }^{35}$

Binding patterns of the WGA-lectin indicated the presence of GlcNAc at the cell surfaces of mucous surface, chief, neck and parietal cells. However, chief cells were not stained with PAS or PAS-AB. This can be also observed in the bat $R$. ferrumequinum. ${ }^{42}$ In accordance with other studies this indicates that specific lectins are more sensitive tools to study glycoconjugates than histochemical stains. ${ }^{56,65}$ Therefore, results of PAS and PAS-AB staining do not necessarily correlate with lectin-binding results. In the central lumen of the stomach structures rich in GalNAc and with no peripheral GlcNAc were detected. PAS-AB staining demonstrated that gastric mucus contained neutral and acid glycoconjugates. In comparison to our results the mucus distribution in the stomach of $R$. ferrumequinum differs in some aspects, e.g., the WGA-lectin binds the cytoplasm of parietal cells. This confirms the great variability concerning the mucus distribution in bat species. ${ }^{36}$

\section{Intestine}

Small and large intestine were not externally distinguishable. In accordance with observations in other bat species, the diameter of the short intestine hardly changes along the whole tube. ${ }^{31}$ In most mammals, an important collection of lymphoid cells, the Peyer's patches, are present in the intestine. They are located in the submucosa and lamina propria of the small intestine and they are essential for initiation and regulation of immune responses. ${ }^{66}$ However, no lymphoid tissue along the whole tube was observed. Similar results were demonstrated for the bat Rhinolophus hildebrandtii. ${ }^{31}$

On the basis of the relative position in the abdomen and the microscopic analysis the small intestine could be divided into duodenum, jejunum-ileum and ileum-colon. Brunner's glands were absent in the submucosa of the duodenum of $P$. pipistrellus. These glands are mammalian-specific. ${ }^{50,67}$ In some bats they are restricted to the very initial part of the duodenum directly after the pylorus. ${ }^{34}$ In this part, only duodenal glands (crypts of Lieberkühn) but no Brunner's glands were found. However, as the tissue sections were cut into blocks, it is possible that the glands could have been only observed in that small part of the duodenum which was not analysed. The small intestine was organised in villi and crypts of Lieberkühn with decreasing number of both along the tube. Both structures increase the intestinal surface, especially in the duodenum. The shape of villi varies

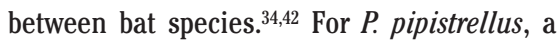
zigzag formation of densely packed villi was found. Since the main absorption of nutrients takes place in the duodenum ${ }^{68}$ this formation may contribute to a high absorption efficiency and a reduction of retention time of food in the intestine. ${ }^{42}$ The absorption is provided mainly via the absorptive enterocytes ${ }^{69}$ in the columnar organised epithelium. After the small intestine, a straight large intestine followed. It consisted only of colon and rectum and lacked a caecum and appendix. The latter phenomenon is already described for Chiroptera ${ }^{70}$ In some bat species, the large intestine may even only consist of the rectum. ${ }^{42,71}$ However, this is discussed controversially in the literature..$^{31,34}$

The main function of the large intestine is the absorption of water and electrolytes. ${ }^{72} \mathrm{~A}$ reduction of this organ could be an adaption to the low amount of water in insects. ${ }^{31,71}$ Additionally, a short colon-rectum has lower maintenance costs and the load carried during locomotion is reduced. ${ }^{23}$ Similar reductions in GI tract mass are described for other insectivorous species. For example, a short GI tract could be an adaption to climbing habits in the shrew Crocidura cyanea. ${ }^{73}$ Villi disappeared in the large intestine in contrast to the crypts, which are responsible for absorption of nutrients and secreting of mucus. ${ }^{74}$

Mucus acts as a barrier to protect underlying layers from damage and invading pathogens..$^{75}$ It consists of mucin glycoproteins and is produced especially by goblet cells. Beside simple columnar absorptive enterocytes these goblet cells were found in the epithelium lining the intestinal mucosa. The number of goblet cells increased along the intestine, with changing characteristics of the secreted glycoconjugates. Generally, many different cell types secreted intestinal mucus. The parts of the intestine differed in the amount of histochemical detectable neutral and acid glycoconjugates and in lectin-binding patterns, indicating a variable mixture of different carbohydrates. From stomach to jejunum-ileum the mucus was a mixture of neutral and acid carbohydrates. Further on the amount of neutral carbohydrates decreased towards the large intestine. These findings correlate with studies on many other mammals. ${ }^{61,73}$ In the colon-rectum section from base to the top of crypts mucus was less acid until it was neutral in the lumen.

In the duodenum the mucus protects the tissue against the acidic compounds from the stomach and lubricates the area..$^{50}$ This explains the neutral character of the secreted mucus. In contrast, in the colon large bacteria colonies can be found. ${ }^{76}$ Acid carbohydrates found in this part of the intestine could increase mucous gel viscosity, ${ }^{73}$ building a barrier from luminal contents like bacteria and 
toxins. ${ }^{77}$ In the colonic lumen, the alkaline character could be a consequence of the degrading of mucin components by enteric bacteria. ${ }^{78}$ Changes in the composition of the mucus could also be seen in the lectin-binding patterns. GalNAc was present in the glycocalyx of enterocytes along the whole small intestine but was absent from these cells in the large intestine. Except for the large intestine, where GalNAc residues were only found at the surface of goblet cells, they were present in the cytoplasm of these cells in the complete intestine. GlcNAc residues were very dominant in the GI tract of $P$. pipistrellus as they were detected at all intestinal cell surfaces and in luminal mucus with the exception of enterocytes in the jejunum-ileum. In addition, the cytoplasm of goblet cells of all intestinal parts reacted with the WGA-lectin suggesting the presence of GlcNAc residues. This phenomenon is controversially discussed in the literature because similar binding patterns were observed for other mammals ${ }^{42,79}$ but not for all. ${ }^{50}$ In addition, comparable results were demonstrated for $R$. ferrumequinum. ${ }^{42}$ The authors hypothesize that a different composition of mucus indicate a change in the physiological function from lubrication to absorption.

\section{Concluding remarks}

Due to energetical limitations, insectivorous bats have some remarkable adaptions concerning food transit time, ${ }^{21}$ digestive efficiency, $^{24}$ and nutrient absorption rates. ${ }^{19}$ Histological, histochemical analysis and lectinbinding patterns demonstrated a shortening of the GI tract, a lack of obvious lymphoid tissue, the absence of glands in many regions, and distinct mucus secreting areas. Together the results indicate different physiological functions of these GI tract areas. To conclude, the simple GI tract of $P$. pipistrellus demonstrated an anatomical reduction of tissue comparable to other insectivorous species, probably representing the ancestral condition.

\section{References}

1. Karasov WH. Energetics, physiology and vertebrate ecology. Trends Ecol Evol 1986;1:101-4.

2. Veloso C, Bozinovic F. Dietary and digestive constraints on basal energy metabolism in a small herbivorous rodent. Ecology 1993;74: 2003-10.

3. Lambert JE. Primate digestion: interactions among anatomy, physiology, and feeding ecology. Evol Anthropo 1998;7:8-20.

4. Smith DM, Grasty RC, Theodosiou NA, Tabin
CJ, Nascone-Yoder NM. Evolutionary relationships between the amphibian, avian, and mammalian stomachs. Evol Dev 2000;2: 348-59.

5. Starck JM. Shaping up: how vertebrates adjust their digestive system to changing environmental conditions. Anim Biol 2003; 53:245-57.

6. Karasov WH, Martínez del Rio C, CaviedesVidal E. Ecological physiology of diet and digestive systems. Annu Rev Physiol 2011;73:69-93.

7. Pérez-Barbería FJ, Gordon IJ, Illius AW. Phylogenetic analysis of stomach adaptation in digestive strategies in African ruminants. Oecologia 2001;129:498-508.

8. Langer P. Lactation, weaning period, food quality and digestive tract differentiations in Eutheria. Evolution 2003;57:1196-215.

9. Chivers DJ, Hladik CM. Morphology of the gastrointestinal tract in primates: comparisons with other mammals in relation to diet. J Morphol 1980;166:337-86.

10. Lavin SR, Karasov WH, Ives AR, Middleton KM, Garland T. Morphometrics of the avian small intestine compared with that of nonflying mammals: a phylogenetic approach. Physiol Biochem Zool 2008;81:526-50.

11. Walters J, Marais S, Johnson O, Bennett NC, Alagaili AN, Mohammed OB, et al. The comparative gastrointestinal morphology of five species of muroid rodents found in Saudi Arabia. J Morphol 2014;275:980-90.

12. Schondube JE, Herrera-M LG, Martínez del Rio C. Diet and the evolution of digestion and renal function in phyllostomid bats. Zoology. 2001;104(1):59-73.

13. Gadelha-Alves R, Rozensztrauch AMDS, Rocha-Barbosa 0. Comparative intestinal histomorphology of five species of phyllostomid bats (Phyllostomidae, Microchiroptera): ecomorphological relations with alimentary habits. Int J Morphol. 2008;26(3):591-602.

14. Thomas SP. Metabolism during flight in two species of bats, Phyllostomus hastatus and Pteropus gouldii. J Exp Biol 1975;63:273-93.

15. Forman GL. Comparative morphological and histochemical studies of stomachs of selected North American bats. Univ Kans Sci Bul 1972;49:591-729.

16. Klite PD. Intestinal bacterial flora and transit time of three neotropical bat species. J Bacteriol 1965;90:375-9.

17. Caviedes-Vidal E, McWhorter TJ, Lavin SR, Chediack JG, Tracy CR, Karasov WH. The digestive adaptation of flying vertebrates: high intestinal paracellular absorption compensates for smaller guts. Proc Natl Acad Sci USA 2007;104:19132-7.

18. Caviedes-Vidal E, Karasov WH, Chediack JG, Fasulo V, Cruz-Neto AP, Otani L. Paracellular absorption: a bat breaks the mammal paradigm. PloS One 2008;3:e1425.
19. Fasulo V, Zhang Z, Chediack JG, Cid FD, Karasov WH, Caviedes-Vidal E. The capacity for paracellular absorption in the insectivorous bat Tadarida brasiliensis. J Comp Physiol B Biochem Syst Environ Physiol 2013;183: 289-96.

20. Speakman JR, Thomas DW. Physiological ecology and energetics of bats, p. 430-90. In: TH Kunz, MB Fenton (eds.) Bat ecology. The University of Chicago Press, Chicago: 2003.

21. Roswag A, Becker NI, Encarnação JA. Interand intraspecific comparisons of retention time in insectivorous bat species (Vespertilionidae). J Zool 2012;288:85-92.

22. Guillemette M. Digestive-rate constraint in wintering common eiders (Somateria mollissima): implications for flying capabilities. Auk 1994;111:900-9.

23. Sibly RM. Strategies of digestion and defecation, p. 109-39. In: CR Townsend, P Calow (eds.) Physiological ecology. Blackwell Scientific, Oxford: 1981.

24. Becker NI, Encarnação JA, Kalko EKV, Tschapka M. The effects of reproductive state on digestive efficiency in three sympatric bat species of the same guild. Comp Biochem Physiol Part A Mol Integr Physiol 2012;162: 386-90.

25. Harwood RH. The effect of temperature on the digestive efficiency of three species of lizards, Cnemidophorus tigris, Gerrhonotus multicarinatus and Sceloporus occidentalis. Comp Biochem Physiol A Physiol 1979;63A: 417-33.

26. Robbins CT. Wildlife feeding and nutrition, 2nd ed.: Academic Press, San Diego: 2001.

27. Dietz C, Nill D, von Helversen 0. Bats of Britain, Europe and Northwest Africa. A \& C Black, London: 2009.

28. Strobel S, Roswag A, Becker NI, Trenczek TE, Encarnação JA. Insectivorous bats digest chitin in the stomach using Acidic Mammalian Chitinase. PLoS One 2013;8: e72770.

29. Vaughan N. The diets of British bats (Chiroptera). Mammal Rev 1997;27:77-94.

30. Stevens CE, Hume ID. Comparative physiology of the vertebrate digestive system. 2nd ed. Cambridge University Press, New York: 1996.

31. Makanya AN, Maina JN. The morphology of the intestine of the insectivorous horseshoe bat (Rhinolophus hildebrandti, Peters): a scanning electron and light microscopic study. Afr J Ecol 1994;32:158-68.

32. Forman GL. Studies of gastric morphology in North American Chiroptera (Emballonuridae, Noctilionidae and Phyllostomatidae). J Mammal 1971;54:909-23.

33. Stutz H, Zisweiler V. Morphological and histological investigations of the digestive tract of Middle European bats (Mammalia: Chiroptera). Myotis 1984;21-22:41-6.

34. Ishikawa K, Matoba M, Tanaka H, Ono K. 
Anatomical study of the intestine of the insect-feeder bat, Myotis frater kaguae. J Anat 1985;142:141-50.

35. Ito $\mathrm{S}$, Winchester RJ. The fine structure of the gastric mucosa in the bat. J Cell Biol 1963;16:541-77.

36. Forman GL. Histochemical differences in gastric mucus of bats. J Mammal 1971;52:191-3.

37. Rouk CS, Glass BP. Comparative gastric histology of five North and Central American bats. J Mammal 1970;51:455-72.

38. McMillan GL, Churchill EP. The gross and histological structure of the digestive system of the little brown bat. Proc S Dak Acad Sci 1947;26:103-9.

39. Hutson AM, Spitzenberger F, Aulagnier S, Coroiu I, Karata $\square$ A, Juste J, et al. Pipistrellus pipistrellus. The IUCN Red List of Threatened Species: 2008 [updated 2008 ver. 2014.3; cited ver. 2012.2]. Available from: www.iucnredlist.org

40. Bhide SA. Anatomy, histology and some aspects of histochemistry of the stomach in two primitive microchiroptera. Proc Indian Acad Sci 1980;89:563-74.

41. Fischer J, Klein PJ, Vierbuchen M, Skutta B, Uhlenbruck G, Fischer R. Characterization of glycoconjugates of human gastrointestinal mucosa by lectins. I. Histochemical distribution of lectin binding sites in normal alimentary tract as well as in benign and malignant gastric neoplasms. J Histochem Cytochem 1984;32:681-9.

42. Scillitani G, Zizza S, Liquori GE, Ferri D. Lectin histochemistry of gastrointestinal glycoconjugates in the greater horseshoe bat, Rhinolophus ferrumequinum (Schreber, 1774). Acta Histochem 2007;109:347-57.

43. Danguy A, Lenglet G, Kiss Jr R, De Launoit Y, Na Kongo M, Kiss Sr R. Distribution of fluorochrome-coupled lectins in the gastrointestinal tract of African bats. Arch Biol 1987;981:53-66.

44. Mulisch M, Welsch U. Romeis. Mikroskopische Technik. 18 ed. Spektrum Akademischer Verlag, Heidelberg: 2010.

45. Myers R. Special stain techniques for the evaluation of mucins. Journal [serial on the Internet]. Available from: http://www. leicabiosystems.com/pathologyleaders/special-stain-techniques-for-the-evaluation-ofmucins/

46. Spicer SS, Schulte BA. Diversity of cell glycoconjugates shown histochemically: a perspective. J Histochem Cytochem 1992;40:1-38.

47. Hammarström S, Kabat EA. Purification and characterization of a blood-group A reactive hemagglutinin from the snail Helix pomatia and a study of its combining site. Biochemistry 1969;8:2696-705.

48. Burger MM, Goldberg AR. Identification of a tumor-specific determinant on neoplastic cell surfaces. Proc Natl Acad Sci USA 1967;
57:359-66.

49. Greenaway PJ, LeVine D. Binding of N-acetylneuraminic acid by wheat-germ agglutinin. Nature 1973;241:191-2.

50. Schumacher U, Duku M, Katoh M, Jörns J, Krause WJ. Histochemical similarities of mucins produced by Brunner's glands and pyloric glands: a comparative study. Anat Rec 2004;278A:540-50.

51. Brooks SA, Hall DMS. Lectin histochemistry to detect altered glycosylation in cells and tissues, p. 49-65. In: SA Brooks, U Schumacher (eds.) Metastasis research protocols. Humana Press, Totowa: 2001.

52. Goetsch E. The structure of the mammalian oesophagus. Am J Anat 1910;10:1-40.

53. Al-Tikriti MS, Khamas W, Chebolu S, Darmani NA. Histomorphology and immunohistochemistry of the lower esophageal sphincter of the least shrew (Cryptotis parva). Cells Tissues Organs 2013;198:390-7.

54. Voigt CC, Sörgel K, Dechmann DKN. Refueling while flying: foraging bats combust food rapidly and directly to power flight. Ecology 2010;91:2908-17.

55. Phillips CJ, Phillips CD, Goecks J, Lessa EP, Sotero-Caio CG, Tandler B, et al. Dietary and flight energetic adaptations in a salivary gland transcriptome of an insectivorous bat. PLoS One 2014;9:e83512.

56. Poorkhalkali N, Jacobson I, Helander HF. Lectin histochemistry of the esophagus in several mammalian species. Anat Embryol. 1999;200(5):541-9.

57. Orlando RC, Bryson JC, Powell DW. Mechanisms of $\mathrm{H}+$ injury in rabbit esophageal epithelium. Am J Physiol. 1984;246(6 Part 1):G718-G24.

58. Zhang XS, Proctor GB, Garrett JR, Schulte BA, Shori DK. Use of lectin probes on tissues and sympathetic saliva to study the glycoproteins secreted by rat submandibular glands. J Histochem Cytochem 1994;42:1261-9.

59. Squier CA, Kremer MJ. Biology of oral mucosa and esophagus. J Natl Cancer Inst Monogr 2001;2001:7-15.

60. Scillitani G, Zizza S, Liquori GE, Ferri D. Histochemical and immunohistochemical evidence for a gradient in gastric juice production in the greater horseshoe bat, Rhinolophus ferrumequinum (Schreber, 1774). Acta Chiropt 2005;7:301-8.

61. Sheahan DG, Jervis HR. Comparative histochemistry of gastrointestinal mucosubstances. Am J Anat 1976;146:103-31.

62. Babkin BP, Komarov SA. The influence of gastric mucus on peptic digestion. Can Med Assoc J 1932;27:463-9.

63. Jass JR, Filipe MI. The mucin profiles of normal gastric mucosa, intestinal metaplasia and its variants and gastric carcinoma. Histochem J 1981;13:931-9.

64. Montagne L, Piel C, Lallès JP. Effect of diet on mucin kinetics and composition: nutrition and health implications. Nutr Rev 2004;62:105-14.

65. Schünke M, Schumacher U, Tillmann B. Lectin-binding in normal and fibrillated articular cartilage of human patellae. Virchows Archiv A 1985;407:221-31.

66. Kararli TT. Comparison of the gastrointestinal anatomy, physiology, and biochemistry of humans and commonly used laboratory animals. Biopharm Drug Dispos 1995;16:351-80.

67. Krause WJ. Biology of the duodenal (Brunner's) glands, p. 67-84. In: PM Motta, H Fujita (eds.) Ultrastructure of the digestive tract. Martinus Nijhoff Publishing, Boston: 1988.

68. Caspary WF. Physiology and pathophysiology of intestinal absorption. Am J Clin Nutr 1992;55:299S-308S.

69. Martín-Villa J, Ferre-López S, López-Suárez J, Corell A, Pérez-Blas M, Arnaiz-Villena A. Cell surface phenotype and ultramicroscopic analysis of purified human enterocytes: a possible antigen-presenting cell in the intestine. Tissue Antigens 1997;50:586-92.

70. Oppel A. [Lehrbuch der vergleichenden mikroskopischen Anatomie der Wirbeltiere: Schlund und Darm].[Book in German]. Gustav Fischer Verlag, Jena: 1897.

71. Okon EE. Functional anatomy of the alimentary canal in the fruit bat, Eidolon helvum, and the insect bat, Tadarida nigeriae. Acta Zool 1977;58:83-93.

72. Shields R. Absorption and secretion of electrolytes and water by the human colon, with particular reference to benign adenoma and papilloma. Brit J Surg 1966;53):893-7.

73. Boonzaier J, Van der Merwe EL, Bennett NC, Kotzé SH. A comparative histochemical study of the distribution of mucins in the gastrointestinal tracts of three insectivorous mammals. Acta Histochem 2013;115:549-56.

74. Florey HW, Harding HE. Further observations on the secretion of Brunner's glands. J Pathol Bacteriol 1933;39:255-76.

75. McGuckin MA, Lindén SK, Sutton P, Florin TH. Mucin dynamics and enteric pathogens. Nat Rev Microbiol 2011;9:265-78.

76. Sakata T, Engelhardt WV. Luminal mucin in the large intestine of mice, rats and guinea pigs. Cell Tissue Res 1981;219:629-35.

77. Specian RD, Oliver MG. Functional biology of intestinal goblet cells. Am J Physiol Cell Physiol 1991;260:C183-C93.

78. Hoskins LC, Zamcheck N. Bacterial degradation of gastrointestinal mucins. I. Comparison of mucus constituents in the stool of germ-free and conventional rats. Gastroenterology 1968;54:210-7.

79. Etzler ME. Lectins as probes in studies of intestinal glycoporteins and glycolipids. Am J Clin Nutr 1979;32:133-8. 